\title{
Concepciones sobre la Historia en Primaria: La epistemología como asunto clave en la formación inicial de maestros $^{1}$
}

\author{
Miguel Ángel Suárez Suárez
}

Universidad de Oviedo

\begin{abstract}
Resumen: La discordancia entre el papel educativo que se atribuye a la Historia y la realidad de las aulas provoca que los estudiantes no perciban ni valoren la utilidad de la disciplina. En la enseñanza primaria, este problema tiene su base en el desconocimiento de la epistemología disciplinar, que limita la capacidad de los maestros para extraer todo el potencial educativo de la historia. En este sentido, desarrollamos una intervención que, partiendo de las concepciones previas de los futuros maestros, revela la pertinencia de iniciarles en la construcción del conocimiento histórico, trabajando actividades para ser competentes en la formulación de hipótesis, la explicación causal y la comparación pasado-presente. Asimismo, los resultados ponen de manifiesto la necesidad de seguir desarrollando estrategias para lograr una transformación efectiva de la enseñanza.
\end{abstract}

Palabras clave: Potencial educativo de la Historia, formación inicial de maestros, construcción del conocimiento histórico, transformación de la enseñanza.

\begin{abstract}
The noticeable difference between the educational role attributed to History and the day-to-day reality of the classroom means that the students do not perceive, or value, the usefulness of discipline. At primary school level, this problem lies in the fact that many teachers are unaware of how to discipline, which in turn limits their capacity to take advantage of History's educational potential as a whole. To combat this problem, I have developed a plan that takes this into consideration and reveals the importance of future teachers being aware of how knowledge of History is constructed. The plan entails developing activities that will develop the teachers' competencies in several key areas, those being: the formulation of hypotheses, the causal explanation and the past-present comparison. Furthermore, the results make it clear that it is paramount to keep developing strategies to reach an effective transformation of the educational system.
\end{abstract}

Key Words: History's educational potential, initial teachers' training, construction of knowledge about History, transformation of the educational system.

(Fecha de recepción: abril, 2012, y de aceptación: septiembre, 2012)

DOI: 10.7203/DCES.26.1932

${ }^{1}$ Este trabajo ha sido posible gracias a una beca predoctoral concedida por la Universidad de Oviedo, dentro de su Programa de Promoción de la Investigación 2011. Asimismo, no hubiéramos podido realizarlo sin la colaboración de la profesora Roser Calaf Masachs, quien nos permitió impartir la correspondiente docencia con su grupo de estudiantes y supervisó todo el proceso de intervención educativa. 


\section{El papel de la Historia}

Si hay una cuestión básica en la didáctica de cualquier disciplina es, sin duda, la función que tiene en materia educativa. Lo es no sólo porque su presencia y configuración en los planes de estudio depende de la utilidad que se le otorgue, sino también porque, evidentemente, de su función derivará la enseñanza misma de la disciplina. Todas las materias escolares desempeñan una labor de indudable importancia en la formación de nuestros jóvenes, y así debe transmitirse a quienes las estudian. Sin embargo, en algunos casos encontramos ciertas contradicciones entre el papel que se les atribuye y su enseñanza, lo que acaba influyendo negativamente en la concepción que los estudiantes en particular, y la sociedad en general, tienen de una determinada disciplina. Y con ello puede llegar a cuestionarse su utilidad didáctica e incluso relativizarse la necesidad de su presencia en los currículos, consecuencia de esa infravaloración que impide aprovechar todo su potencial educativo. En cierto modo, es lo que ocurre con disciplinas como la que nos ocupa: la Historia.

Por supuesto, no creemos en absoluto que se esté cuestionando el estudio de la Historia en Primaria y Secundaria. En cambio, sí que existe esa contradicción a la que hemos aludido, lo que supone a nuestro juicio un duro lastre de cara a su enseñanza. Si nos preguntamos las razones por las cuales se estudian las Matemáticas, el Inglés o la Química, por citar algunos ejemplos, comprobaremos que, en líneas generales, la utilidad justificada por los expertos (docentes e investigadores) y las concepciones de los estudiantes -al margen de las posibles preferencias y gustos personalesposeen un alto grado de coincidencia: pocos dudarán de que las Matemáticas, por su omnipresencia, son imprescindibles; de que el Inglés, por su condición de idioma universal, es básico; o de que la Química es fundamental para observar cómo se comportan ciertos elementos, muchos de los cuales forman parte de nuestra vida diaria. Es decir, se trata de materias que tienen una incidencia palpable y positiva en la cotidianeidad del estudiante.

Pero, ¿por qué decimos que no ocurre lo mismo con la Historia? La razón es que existen notables diferencias entre las concepciones de quienes desarrollamos nuestro trabajo en torno a la disciplina y su enseñanza y lo que perciben los destinatarios de nuestras acciones (los alumnos). En nuestro caso, sabemos y mantenemos que la historia -la conciencia histórica- no sólo es una de las facultades inherentes a las sociedades humanas, sino también «un componente decisivo de su presente, de su sentido de la identidad, de sus instituciones y tradiciones y de sus relaciones con el medio físico y con otros grupos humanos circundantes (Moradiellos, E., 2011: 34)».

Y, precisamente, de esta condición se deriva la particularidad que confiere a la disciplina su mayor potencial educativo, que repetimos también en incontables ocasiones: conocer y comprender nuestro pasado nos sitúa en una posición privilegiada para entender nuestro presente. Básicamente porque el estu- 
dio del pasado permite captar la esencia del comportamiento de las sociedades pretéritas: las tensiones sociales, económicas, etc., las motivaciones humanas y las consecuencias de sus acciones, los cambios y permanencias... Pero lo más importante es que al analizar el pasado los estudiantes adquieren conciencia de la complejidad propia de las relaciones humanas, al tiempo que aprenden a utilizar diversas herramientas propias de la investigación social (Prats y Santacana, 2011: 20-25). Lo cual, facilita que puedan responder a ciertos porqués del presente y «conocer los problemas que la sociedad ha heredado del pasado para aprender a construir un mundo mejor (Valls y López Facal, 2011: 198)». Es decir, que al igual que las disciplinas utilizadas como ejemplo anteriormente, no cabe duda de que la Historia también puede tener una incidencia palpable y útil en la cotidianeidad de los estudiantes.

\section{Para qué enseñamos historia (todavía) hoy}

Sin embargo, ¿es esta la idea que se está transmitiendo al alumnado? Desde luego, la situación nos impide responder afirmativamente. A pesar de que su utilidad parece evidente, los estudiantes no la perciben y, en el mejor de los casos, siguen concibiendo la materia como un conjunto de datos que proporcionan una cierta cultura general (Merchán, 2007), pero poco más (es de sobra conocida, por ser de dominio público, esa peculiar relación entre el historiador y el Trivial, identificando la historia con un simple anecdotario). Por tanto, es innegable que algo no funciona, que existe una contradicción entre lo que piensan los educadores y lo que perciben los estudiantes. Resultaría complicado tratar aquí todos los factores que pueden influir en esta situación; si bien, en la base del problema se encuentra el claro desequilibrio existente entre la formación disciplinar y la preparación didáctica de los docentes (Valls, 2004), a favor de la primera en Secundaria y de la segunda en Primaria.

En el caso de la Secundaria, algunos estudios han revelado ciertas dificultades para introducir a los estudiantes en el uso de las herramientas conceptuales más básicas de la disciplina histórica. En un reciente trabajo centrado en la causalidad histórica, Montanero, Lucero y Méndez (2008) apuntaban que los profesores de Historia, en líneas generales, conocen los mecanismos causales y los integran en sus explicaciones. Sin embargo, a la hora de implementar estrategias para comprobar y favorecer la comprensión y asimilación de este concepto, los investigadores admiten que la situación dista de ser satisfactoria.

Asimismo, F. Javier Merchán (2002) señala cómo en el discurso profesional (lo que los profesores/as de Secundaria opinan sobre la enseñanza de su asignatura) predominan las referencias al potencial de la Historia para ayudar a comprender el presente, desarrollar en los alumnos la capacidad de razonamiento lógico y promover una serie de valores necesarios para la formación de una ciudadanía tolerante. $\mathrm{Y}$ al mismo tiempo, la mayoría considera que el 
objeto fundamental de la asignatura es, simplemente, conocer los hechos históricos y las grandes etapas y períodos de la historia (Merchán, 2002: 46-48). Parece claro, pues, que conocer el pasado es suficiente para alcanzar la finalidad que se atribuye a la enseñanza de la historia.

En cualquier caso, consideramos que estos planteamientos no son del todo erróneos, aunque, como decimos, sí son el resultado de prestar poca atención a los avances de la Didáctica. En verdad, la licenciatura o grado en Historia proporciona a quien la estudia las claves para comprender nuestro presente -y el de otros colectivos o sociedades- como parte de un decurso más o menos amplio, fruto de una determinada trayectoria histórica y causa de lo que sucederá en el futuro; idea que engloba todas las virtudes señaladas anteriormente. Y ello sin recurrir, por lo general, a estrategias que no sean la exposición unidireccional de contenidos por parte del profesor. Es decir, podríamos afirmar que la utilidad que defienden los docentes de Secundaria y que nosotros compartimos, forma parte de un potencial implícito que puede hacerse efectivo al estudiar en profundidad la disciplina.

Pero no podemos olvidar que al trabajar con escolares, diversos factores (desde los puramente cognitivos que impiden abarcar toda la complejidad disciplinar, hasta las limitaciones de tiempo, que debe compartirse con otras materias) favorecen que ese potencial permanezca latente, pues hacen imposible estudiar historia en profundidad. Por tanto, el papel del profesorado no puede reducirse a explicar el pasado, sino que además debe hacer explícito el potencial educativo de la historia. Y es aquí donde la enseñanza (tanto los currículos escritos y la formación del profesorado, como la propia práctica escolar) más se resiente.

En relación con lo anterior, ¿qué ocurre con los maestros de Primaria cuyo último contacto con la disciplina fue en Bachillerato? En este caso, sucede lo contrario que en Secundaria: su formación pedagógica es superior, pero la formación disciplinar es, evidentemente, muy inferior. Y, además, su última experiencia con la historia fue un aprendizaje memorístico con la única finalidad de prepararse para aprobar la selectividad. Así, el problema se retroalimenta: las dificultades que encontramos en Secundaria se transmiten también a Primaria, incidiendo en la concepción de los maestros sobre la disciplina y, en consecuencia, en su práctica docente.

Pero también existe otro problema en Primaria: buscar alternativas a la enseñanza tradicional (utilización exclusiva del libro de texto) puede generar en los maestros una cierta inseguridad derivada del desconocimiento de la disciplina y de estrategias concretas que permitan un mejor aprovechamiento de su potencial didáctico (Feliu y Sallés, 2011). De tal forma que se desaprovecha su preparación didáctica debido a la ausencia de formación disciplinar. Por ello, creemos que en la formación inicial de los maestros debe plantearse la necesidad de abordar este problema desde la raíz, comenzando por aproximarles al verdadero sentido de la Historia. Algo que, como detalla- 
remos a continuación, puede lograrse profundizando en la epistemología de la disciplina.

\section{Intervención educativa: La impor- tancia de la epistemología en la formación inicial de maestros.}

Si se pretende obtener un mínimo de eficacia didáctica $y$, sobre todo, ser consecuente con la finalidad que se atribuye a una disciplina, es esencial conocer sus fundamentos básicos. Los maestros deben ser conscientes, ante todo, de cómo se construyen los conocimientos científicos, ya que su papel no puede reducirse a ser un mero transmisor de datos -algo que, en plena sociedad de la información, incluso carece de sentido-, sino que, precisamente, su labor consiste en enseñar a los alumnos a construir su propio conocimiento utilizando las técnicas que pueden proporcionarle las distintas materias escolares. En el caso de la Historia, además, está presente el problema del pragmatismo: para los estudiantes más jóvenes conocer datos del pasado no tiene, por sí mismo, ninguna utilidad, lo que indudablemente influye en la desmotivación con la que abordan su estudio. De modo que, para poder hacer explícito el potencial educativo - la utilidad, si se quiere- de la disciplina, la aproximación a su epistemología en la formación inicial de maestros es un asunto imprescindible.

En este sentido, llevamos a cabo una intervención con la que pretendíamos mostrar a los futuros maestros cómo se construye el conocimiento históri- co. Las hipótesis de partida fueron las siguientes:

- Desarrollando un modelo basado en la participación activa mediada por el profesor, los estudiantes pueden llegar a desvelar, por sí solos, el potencial educativo de la Historia.

- El conocimiento de la epistemología disciplinar puede promover una reflexión que lleve a los futuros docentes a repensar y transformar su práctica docente.

De igual manera, establecimos unos objetivos muy concretos que hicieran factible la comprobación de las hipótesis:

- Mostrar a los futuros maestros cómo sus concepciones sobre la disciplina influyen y determinan su práctica docente (Guimerà, 1991; González Mangrané, 1993).

- Familiarizar a los futuros docentes con los procedimientos explicativos de la Historia.

- Construir un modelo explicativo para un determinado hecho histórico, teniendo en cuenta la relación causal e intencional que existe entre otros hechos que actúan como precedentes.

- Evaluar la intervención a partir de las reflexiones realizadas por los futuros maestros.

Finalmente, cabe señalar que el trabajo se desarrolló a lo largo de 20 sesiones, con 60 estudiantes de $3^{\circ}$ de Magisterio en la asignatura de Ciencias Sociales y su Didáctica, y constituyó la introducción al bloque de Didáctica de la Historia. 


\subsection{Planificación}

En un principio, para mantener unos niveles lógicos de coherencia entre lo que se enseñaría a los futuros docentes y lo que estos deberían enseñar a sus alumnos, se tuvieron en cuenta algunos trabajos como marco de referencia (Pozo, Asensio y Carretero, 1989; Carretero y Voss, 2004; Lee, 2005; Ashby, Lee y Shemilt, 2005; Levstik y Barton, 2005). No obstante, durante el transcurso de la intervención el nivel de complejidad fue graduándose, sobre todo, según las posibilidades que ofrecían los participantes y no tanto desde el punto de vista del aprendizaje en Primaria. Ello se debe a que no se pretendía enseñar estrategias para la enseñanza, sino conocer el impacto de la intervención y, en consecuencia, las posibilidades y dificultades para introducir cambios en la cotidianeidad docente de los futuros maestros.

Como punto de partida, se establecieron algunas premisas que guiarían la intervención:

- Aun en los niveles más básicos, no es posible enseñar una disciplina en cuyo valor formativo no se cree o se desconoce. Por eso, ayudar a los futuros docentes a descubrir el potencial didáctico de la historia debe considerarse como un paso esencial que dotará de significatividad al resto de formación que reciban.

- La explicación de la historia en el aula no debe entenderse como un axioma, como un discurso cerrado e incuestionable en cuya construcción los estudiantes no desempeñan ningún papel, ya que entraríamos en contradicción con los propósitos educativos de la materia.

- Por tanto, la dinámica del aula no puede basarse en la comunicación unidireccional docente-alumnado, sino que debe fomentarse la participación activa del estudiante. El diálogo, el intercambio de pareceres, es básico para evitar, o al menos limitar, la imposición (intencionada o no) de determinados mensajes o visiones sobre distintos hechos. Abogamos, pues, por potenciar lo que Habermas (1987) denominó acción comunicativa, mediante la cual, todos los participantes adquieren protagonismo en el proceso de construcción de conocimiento a partir de un diálogo intersubjetivo entre iguales.

- La Historia es una disciplina basada en la interpretación de diversas fuentes, materiales o inmateriales. A este respecto, iniciar a los estudiantes en la interpretación de determinados hechos (del pasado o del presente) puede ser útil por varios motivos: en primer lugar, porque aprenden a formular hipótesis; en segundo lugar, porque al contrastar su interpretación con las de sus compañeros, comprenderán que no existe una única visión sobre los hechos ni una única forma de explicarlos; y en tercer lugar, porque una vez realizado lo anterior, la situación hará necesaria la consulta de distintas fuentes de información para verificar o refutar las hipótesis de partida mediante datos fiables. Es decir, conseguiremos una transición más natural hacia el siguiente paso: la crítica y selección de fuentes. 
- La formulación de hipótesis y su comprobación deben dar lugar a una explicación de las conclusiones a las que se llega. Pero dicha explicación no puede ser una reiteración de lo que aparece en el libro o cualquier otra fuente (el tristemente habitual copiar y pegar), sino que, en función de la etapa educativa, habremos de hacer un esfuerzo más o menos complejo por desvelar la relación existente entre distintos hechos. Y, si tenemos en cuenta que toda situación relacionada con el ser humano es fruto de diversas causas y/o motivaciones y a su vez desencadena diversas consecuencias, no cabe duda de que el aprendizaje de la causalidad histórica cobra especial relevancia. Sin olvidar, por supuesto, que para obtener una mayor significatividad en los aprendizajes debemos incidir también en los cambios y permanencias, a fin de comprender la influencia del contexto histórico y la pervivencia de ciertos problemas o situaciones que incluso siguen vigentes en la actualidad. Para lo cual, la comparación de contextos o períodos (diacrónica y/o sincrónica) es un recurso más que interesante (Pagès, 2006).

\subsection{La influencia de las concepciones previas en la enseñanza}

El primer paso era conocer qué idea tenían los estudiantes de Magisterio sobre la disciplina y su enseñanza. Para ello no se recurrió a la habitual pregunta de para qué sirve la Historia, pues podía ocurrir que, al tener que hacer explíci- ta una opinión sobre una pregunta tan fundamental, los alumnos acomodaran su respuesta a un discurso estándar ( $l o$ que el profesor quiere escuchar) que de poco serviría para conocer sus verdaderas concepciones. Por el contrario, escribimos en la pizarra la tan citada frase de Josep Fontana (1973: 82), «[La Historia] tiene por meta explicarnos el pasado para hacernos inteligible el presente y facilitarnos la construcción racional del futuro", y les pedimos que expresaran hasta qué punto estaban de acuerdo con ella. Como era de esperar, el acuerdo fue unánime; en cambio, la incertidumbre apareció cuando se les preguntó por el verdadero significado de esa frase y cómo hacerlo efectivo mediante la enseñanza de la disciplina, a lo que ninguno supo responder. Era evidente, pues, que para los alumnos, consciente o inconscientemente, la disciplina carecía de una utilidad clara. Situación que, tratándose de futuros maestros, se convierte en un problema cuya solución, creemos, debe ser una prioridad.

Por tanto, debíamos profundizar más en esta cuestión a fin de que ellos mismos observaran cómo sus concepciones inciden en la práctica docente. Para ello, partimos de las consideraciones realizadas por Prats (1997: 15): «el estudio de acontecimientos, hechos y personajes puede poseer una destacada utilidad didáctica, como procedimiento para reforzar la adquisición de métodos y técnicas de análisis histórico y, lo que es más importante, para aprender a matizar un campo de observación». Teniendo en cuenta lo anterior, seleccionamos un hecho histórico que todos conocían (la sociedad estamental), proyectamos una 
imagen significativa (Imagen 1) y pedimos a los estudiantes que elaboraran por escrito, en grupos de cinco personas, una explicación que permitiera comprender el significado de la imagen.

\section{Imagen 1: Sociedad estamental}

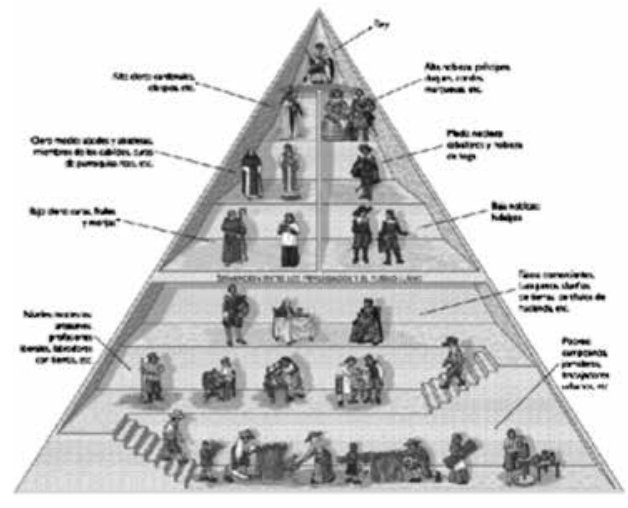

Fuente: Wikipedia.
En el cuadro 1 pueden observarse las categorías utilizadas para agrupar las aportaciones de los alumnos. A este respecto, se establecieron cuatro niveles progresivos atendiendo a la complejidad interpretativa (esfuerzo realizado para interpretar la imagen), de tal forma que la situación deseable sería aquella en la que la totalidad de los futuros maestros incluyera en sus explicaciones todos los elementos señalados. Sin embargo, como se refleja en la Figura 1, en el $100 \%$ de las explicaciones encontramos elementos puramente descriptivos (correspondientes al nivel 1), y de ellas, sólo un 58\% (35 de los 60 participantes) pudo adscribirse al nivel 2 al aportar alguna información más allá de la simple descripción, pero sin realizar un esfuerzo interpretativo destacable.

\section{Cuadro 1: Niveles de complejidad explicativa}

\section{Nivel}

\section{Elementos distintivos}

1 Se describe el recurso utilizado, señalando únicamente aquello que puede observarse en él.

2 Se hace referencia a posibles problemas o situaciones que pueden inferirse del hecho seleccionado para el análisis explicativo.

3 Se formulan hipótesis para explicar las causas que pudieron incidir en el hecho en cuestión, estableciendo un esquema sencillo de causa-consecuencia.

4 Además de todo lo anterior se realiza una interpretación global de todo el proceso, desvelando relaciones implícitas entre los hechos, como las que derivan de la intencionalidad humana. Se construye así una explicación integrada, combinando factores causales y teleológicos (Pozo, Asensio y Carretero, 1986). 


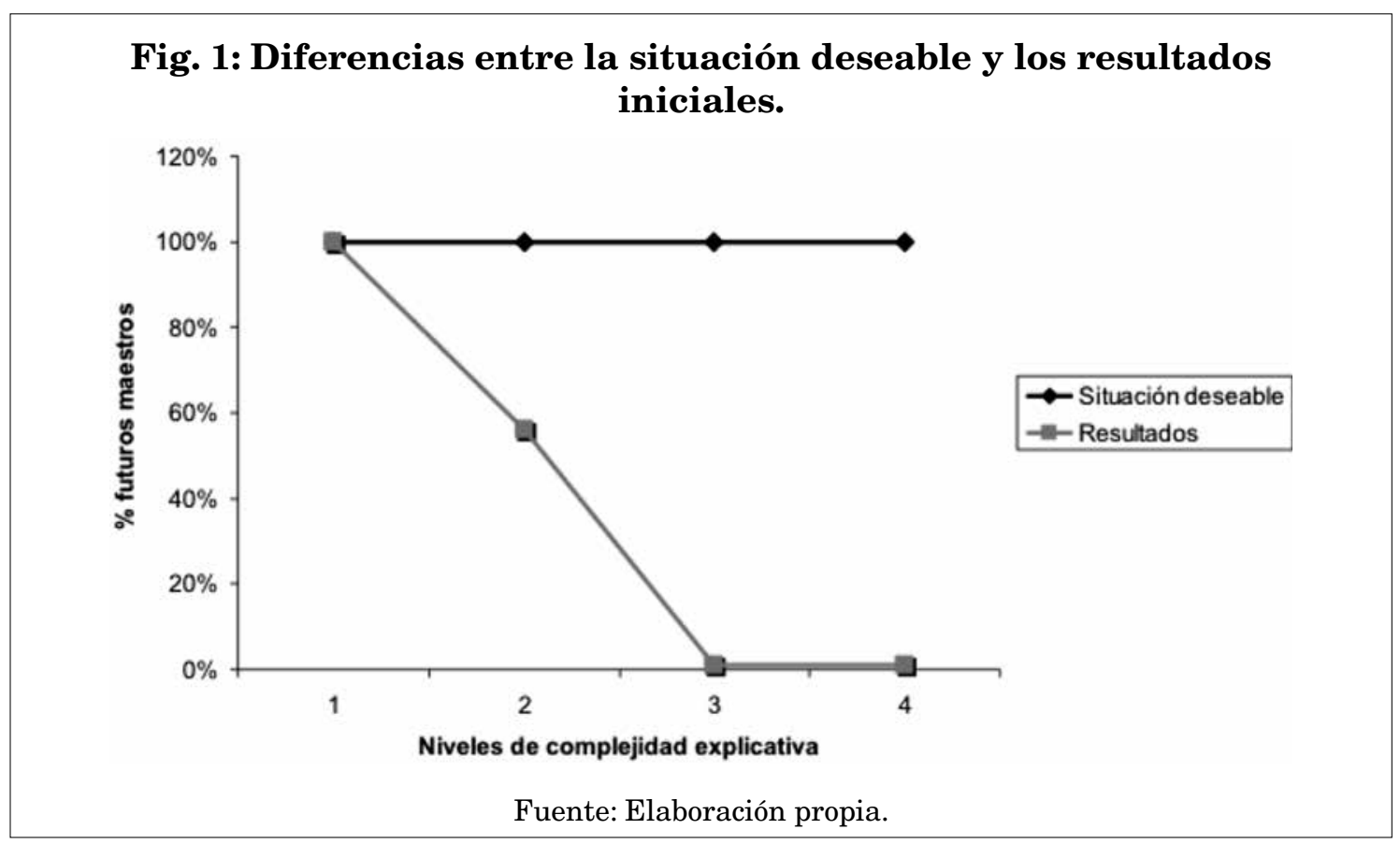

Así pues, los estudiantes realizaron descripciones de la imagen, incidiendo en algunos casos en la desigualdad y la pobreza de ciertos grupos sociales, pero sin referencias a los precedentes o causas que pudieron motivar su desarrollo -aun basándose en hipótesis o suposiciones subjetivas-, ni tampoco a otros factores como la intencionalidad.

Es decir, que para los futuros maestros, enseñar historia consistía en describir qué sucedió en el pasado, obviando las interpretaciones que permiten explicar las relaciones entre los distintos hechos. En otras palabras, lo que se estaría transmitiendo a los alumnos de Primaria sería, en todo caso, una sociología del pasado (Carretero, 2002), que poco tiene que ver con la enseñanza de la historia. Y precisamente, este es el modelo que predomina en las aulas de colegios e institutos y que determina la concepción que los docentes tienen sobre la enseñanza de la disciplina.

\subsection{La formulación de hipótesis y la causalidad como primera apro- ximación a la epistemología de la Historia}

¿Cómo concienciar a los futuros maestros de que la enseñanza de la historia pretende algo más que la simple enumeración de hechos, nombres y fechas? Nosotros hallamos la respuesta con otra pregunta: ¿Cómo se llegó a la situación que nos ocupa (la consolidación de la sociedad estamental)? Al formularles esta cuestión, los alumnos advirtieron que, efectivamente, sus explicaciones sobre la imagen adolecían de cierta falta de solidez, admitiendo que para entender y explicar cualquier situación es 
imprescindible conocer e interpretar las causas de las que deriva; si bien, atribuían este problema al desconocimiento de la historia. Por supuesto, es imposible enseñar algo que no se conoce; pero también hay que saber cómo enseñar lo que uno conoce (Pagès, 2004), ya que de ello dependerá lo que se transmita a los estudiantes. Y para enseñar historia es necesario, ante todo, conocer cómo se construye el conocimiento histórico, porque «la ausencia de los elementos metodológicos de la disciplina -que son el cemento que une los conceptos- hace que el aprendizaje carezca de base epistemológica y se transforme en un conjunto aislado e inconexo de curiosidades (Santacana, 2005: 12)».

Por ello, más que trabajar sobre una visión histórica acabada, nos interesaba que los futuros maestros conocieran el proceso explicativo propio de la disciplina, algunas pautas básicas $\mathrm{y}$, sobre todo, las dificultades que entraña. En este sentido, conviene tener presente que, a pesar de que atribuyeron sus problemas al desconocimiento de la historia, la disciplina no les es ajena: todos la estudiaron durante su escolarización preuniversitaria e, independientemente de la metodología de enseñanzaaprendizaje que les fue aplicada, no podemos dudar de que las informaciones que manejaron eran rigurosas. Con lo cual, todos aquellos hechos históricos que pudieran recordar se apoyarían sobre un mínimo de rigor y serían perfectamente útiles para alcanzar los objetivos propuestos. Se trataba, pues, de activar sus recuerdos y utilizarlos para trabajar algunos procedimientos de la disciplina histórica, lo que tam- bién les permitiría observar, sobre su propia experiencia, la diferencia entre la simple memorización de datos y la utilización de estos para comprender y explicar diversos hechos (Lee, 2005; Ashby, Lee y Shemilt, 2005).

De modo que, tras explicar algunas ideas sobre la causalidad histórica, se les propuso realizar, utilizando los grupos formados anteriormente, un recorrido por la historia de la humanidad cuyo punto de partida debía ser el desarrollo de la agricultura y la ganadería. En él, debían señalar únicamente los hitos que consideraran más relevantes y que, mediante relaciones de causa-efecto, construyeran un esquema explicativo coherente del proceso que desembocó en la formación de la sociedad estamental. Lógicamente, se obtuvieron visiones distintas y con niveles de coherencia dispares, si bien, en este momento lo importante era fomentar la formulación de hipótesis, con el objetivo de hallar las causas que desencadenan o influyen en un determinado hecho. En este sentido, para minimizar los efectos de las teorías implícitas de los alumnos, así como incidir en que la pluralidad de visiones no sólo es habitual sino también necesaria, se realizó una primera puesta en común integrando sus aportaciones en una explicación conjunta basada en inferencias causales básicas.

Para no saturar el texto de información, se muestra el resultado final de este primer proceso explicativo. En el esquema, que realizamos a posteriori (Figura 2 ), aparecen hechos cuyo grado de coincidencia entre los alumnos se situó por encima del 80\% (50 alumnos o más). No obstante, como puede apreciarse, algu- 
nas flechas aparecen fragmentadas. En este caso, se trata de relaciones fácticas que reflejaban un menor grado de coinci- dencia entre los alumnos, aunque superior a otros hechos que excluimos por su carácter marginal.

\section{Fig. 2: Primer esquema causal construido por los estudiantes de Magisterio.}

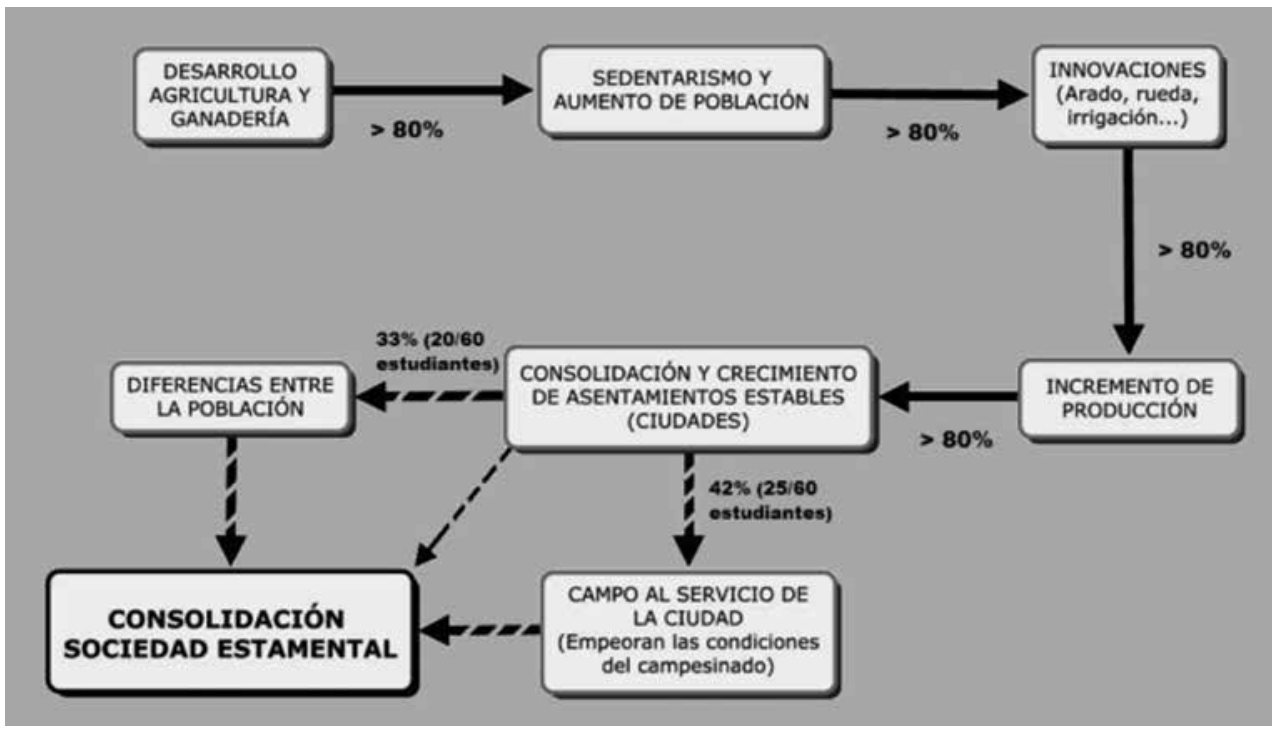

Fuente: Elaboración propia.

En líneas generales, los alumnos no encontraron grandes dificultades para elaborar un esquema sencillo basado en la temporalidad causa-efecto. Sin embargo, los problemas aparecen cuando se deben inferir motivos implícitos que no se corresponden con hechos fácilmente identificables y que requieren una interpretación global de todo el proceso; es decir, contemplar no sólo las causas coyunturales, estructurales, etc., sino también las motivaciones de los actores de la historia (los humanos). Así, parece que el desarrollo de las ciudades -su influencia en la desigualdad social- fue el desencadenante último de la sociedad estamental; pero resulta evidente que un modelo de organización social, así como las leyes y normas que velan por su estabilidad, no surgen de manera natural, sino que en ellas son determinantes las acciones humanas deliberadas, principalmente de aquellos que tienen acceso o detentan el poder. Estaba claro que debía fomentarse el trabajo con inferencias elaborativas más complejas que desvelaran estos contenidos implícitos (Montanero y León, 2004), pero sin recurrir, en la medida de lo posible, al discurso unidireccional. 
3.4. La comparación entre el pasado y el presente para desvelar la importancia de las motivaciones humanas

Para solucionar el problema señalado, se decidió compensar el nivel de abstracción propio del pasado con una mayor concreción que puede encontrarse en situaciones del presente. De esta forma, sería más sencillo implementar procesos empáticos, cuya importancia para captar y comprender las motivaciones humanas es indudable (Levstik y Barton, 2005). Para ello, se proyectaron cuatro fotografías (Imagen 2), aludiendo a un hecho actual que contenía los descriptores más utilizados por los estudiantes para referirse a la sociedad estamental (desigualdad y pobreza). Lo cual, permitiría establecer ciertas comparaciones entre el pasado y el presen- te. A este respecto, para contextualizar las imágenes se extrapolaron las conclusiones del modelo causal que los propios alumnos habían construido para la sociedad estamental (ver Figura 1), incardinándolas en una explicación que resumimos en las siguientes líneas:

«En la actualidad, el crecimiento exponencial de las ciudades ha dado lugar a una mayor desigualdad de oportunidades entre sus habitantes. Asimismo, la creciente población urbana ejerce una presión cada vez más intensa sobre el medio rural de su entorno, empeorando las condiciones de vida de la gente que en ellos habita. Y de igual forma, la progresiva urbanización de unos países ha causado el empobrecimiento de otros».

\section{Imagen 2: Representación gráfica de dos hechos actuales: desigualdad y pobreza.}

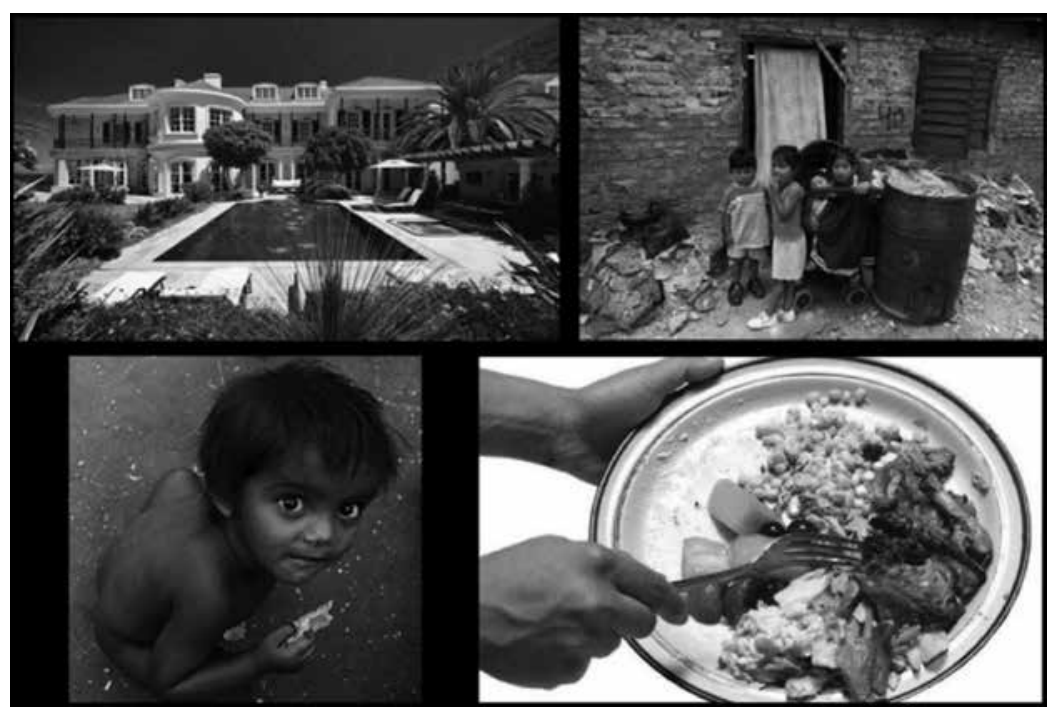

Fuente: Sitios públicos de Internet 
Sin embargo, los alumnos consideraron que tal explicación estaba incompleta, entendiendo que el desarrollo urbanístico no puede ser la única causa que de sentido a un modelo social que mantiene fuertes desigualdades entre las personas. En efecto, al proyectar el análisis sobre el contexto en el que ellos mismos están inmersos (y que por tanto les resulta plenamente significativo) percibieron otras fuerzas que pueden incidir en determinados hechos y que se corresponden con las acciones intencionales de los humanos. De hecho, los estudiantes expusieron y mantuvieron la idea de que los fuertes contrastes representados en las imágenes eran el resultado, principalmente, de los intereses de ciertos sectores de nuestra sociedad. En este sentido, fueron ellos quienes, por iniciativa propia, introdujeron nuevos conceptos como la acumulación de riqueza, la formación de estratos sociales con intereses diferentes y el desarrollo de sistemas amparados en leyes y normas creadas ad hoc, cuyo fin es garantizar la pervivencia de una situación concreta.

El siguiente paso era, pues, incorporar estas últimas aportaciones a la explicación de la sociedad feudal. Se repitió el proceso seguido en el primer esquema causal, solicitando a los estudiantes que elaboraran por escrito una explicación lo más detallada posible para, posteriormente, realizar una puesta en común. Asimismo, se les pidió que escribieran una reflexión sobre la enseñanza de la historia y la utilidad o no de esta práctica para su formación inicial. Esto haría factible analizar, con mayor detenimiento, la incidencia que esta experiencia había tenido en los futuros maestros.

\subsection{Resultado del proceso explicativo}

En un primer momento, los estudiantes manifestaron ciertos problemas a la hora de relacionar los nuevos conceptos extraídos de la observación del presente con el análisis de la sociedad feudal. Problema que atribuimos, fundamentalmente, a la novedad que supuso la referencia al presente para profundizar en temas del pasado; lo cual, se entendió como una nueva actividad independiente del trabajo anterior. Por ello, a fin de minimizar esta dificultad, se proyectó el primer esquema causal para conectar con el trabajo previo, de forma que resultara más sencillo percibir los cambios derivados de la introducción de nuevos conceptos.

A partir de la explicación final, elaboramos un nuevo esquema (Figura 3) prestando especial atención a los cambios que obtuvieron un mayor grado de coincidencia entre los estudiantes. Como vemos, puede inferirse un claro progreso tanto cuantitativo (en el número de hechos considerados), como cualitativo (en las relaciones que se establecen entre los hechos). Así, la totalidad de los estudiantes utilizaron, aunque de distintas maneras, el incremento de la producción para explicar cómo el campesinado, con su trabajo, debe proveer de alimentos a las cada vez más pobladas ciudades, así como a los señores que controlan estas comunidades; lo que indudablemente merma su autonomía al disponer de una menor proporción para el autoconsumo. Y tam- 


\section{Fig 3: Explicación final construida por los estudiantes.}

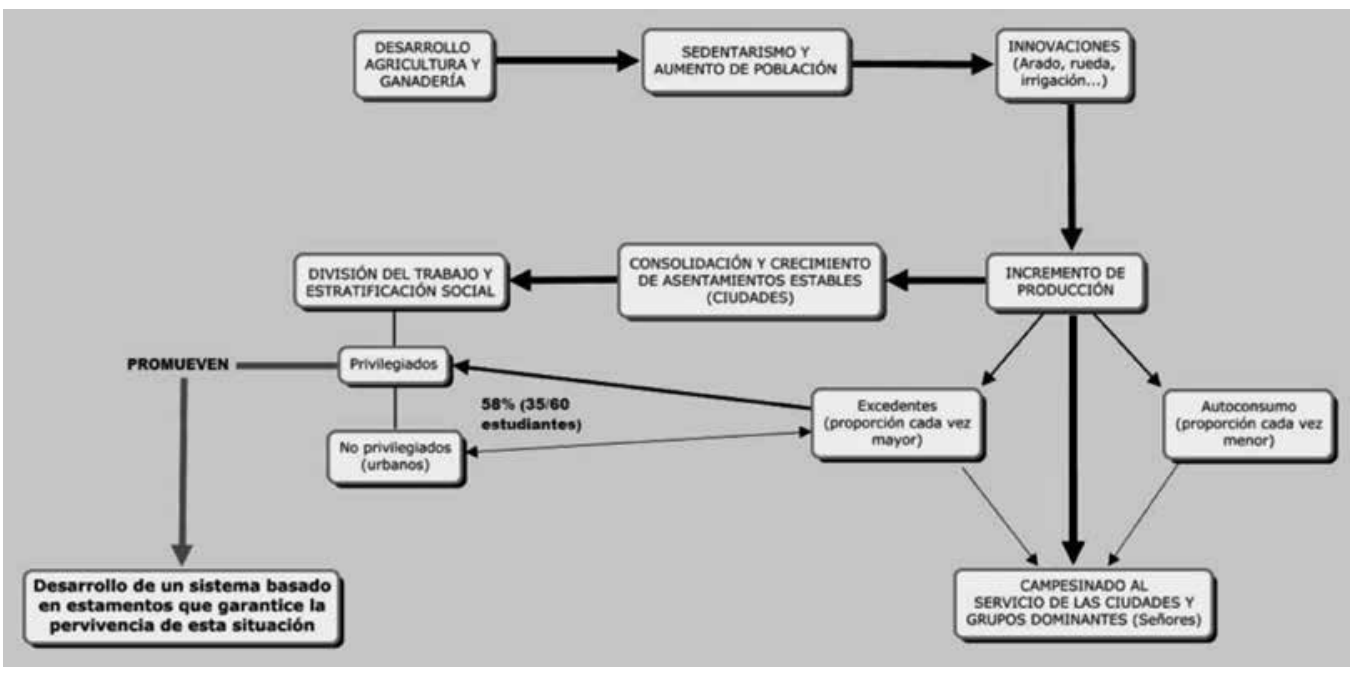

Fuente: Elaboración propia

bién incidieron en que el crecimiento de las ciudades y la consecuente diversificación de trabajos y/o funciones dan lugar a una estratificación social que genera desigualdades.

Sin embargo, el cambio más significativo (que fue mencionado por $35 \mathrm{de}$ los 60 alumnos, un 58\%) lo encontramos en la relación que se construye en torno a los excedentes, que da coherencia a todo el proceso explicativo y donde aparece un indicio de jerarquización: se observa que, en menor medida, parte de los excedentes se dirige a los grupos urbanos no privilegiados, si bien se considera que, como elementos productivos de la sociedad, también contribuyen con su trabajo a la formación de excedentes; en cambio, el trayecto es sólo de ida y más intenso en lo que se refiere a los grupos privilegiados, quienes se benefician de todo el proceso. Y precisamente, es esta relación la que permite comprender el componente intencional que resulta clave en la explicación: los grupos privilegiados, como principales beneficiarios de la situación, aprovechan su posición dominante para promover un inmovilismo social que mantenga ese statu quo.

\section{Resultados de la intervención desde el punto de vista del inves- tigador}

Los resultados muestran que puede hablarse de tres problemas fundamentales que aparecieron durante el transcurso del trabajo (Cuadro 2). Desde nuestra perspectiva, tales problemas derivan, ante todo, del desconocimiento de la epistemología disciplinar. La inseguridad que genera no estar fami- 
liarizado con la construcción del conocimiento histórico, sitúa a los futuros maestros en un papel pasivo en lo que respecta al análisis de los hechos (papel que acaban otorgando, aun inconscientemente, a sus alumnos). Así, se considera que el discurso histórico ya está construido de antemano por los historiadores y no es necesario conocer o preguntarse cómo se ha llegado a él, sino simplemente transmitírselo a los estudiantes. Precisamente, la solución a este problema de base fue una de las prioridades, de ahí que evitáramos trabajar con productos ya acabados, optando por una reconstrucción hipotética de un proceso histórico.

No obstante, aunque la formulación de hipótesis resolvió parcialmente este primer problema, pudo comprobarse

\section{Cuadro 2: Problemas detectados durante la intervención.}

\begin{tabular}{|c|c|c|}
\hline Problema & SOLUCIÓN PROPUESTA & REsultados \\
\hline $\begin{array}{l}\text { Los futuros maestros consi- } \\
\text { deran la explicación histórica } \\
\text { como una descripción o rei- } \\
\text { teración sólo de lo que puede } \\
\text { observarse (una imagen, un } \\
\text { texto, información del manual } \\
\text { escolar, etc.) }\end{array}$ & $\begin{array}{l}\text { Indagar en las posibles causas } \\
\text { que desencadenan o influyen en } \\
\text { un determinado hecho. }\end{array}$ & $\begin{array}{l}\text { Se consigue una primera apro- } \\
\text { ximación a la formulación de } \\
\text { hipótesis. Los futuros maestros } \\
\text { comprenden que los hechos no } \\
\text { pueden tratarse de forma ais- } \\
\text { lada, sino interrelacionados } \\
\text { con otros en un decurso más } \\
\text { o menos amplio. Esto supone, } \\
\text { asimismo, una iniciación al } \\
\text { trabajo con la causalidad his- } \\
\text { tórica. }\end{array}$ \\
\hline $\begin{array}{l}\text { Dificultad para incluir en el } \\
\text { análisis relaciones implíci- } \\
\text { tas entre los hechos, que sólo } \\
\text { pueden desvelarse median- } \\
\text { te la interpretación global de } \\
\text { un determinado proceso (caso } \\
\text { de las acciones intencionales } \\
\text { humanas) }\end{array}$ & $\begin{array}{l}\text { Establecer comparaciones con } \\
\text { hechos del presente, partiendo } \\
\text { de los conceptos más utilizados } \\
\text { inicialmente por los estudian- } \\
\text { tes para referirse a la socie- } \\
\text { dad estamental (desigualdad y } \\
\text { pobreza). }\end{array}$ & $\begin{array}{l}\text { Proyectando el análisis sobre } \\
\text { situaciones del presente (signi- } \\
\text { ficativas), los futuros maestros } \\
\text { perciben la importancia de con- } \\
\text { templar otras fuerzas que pue- } \\
\text { den incidir en los hechos y que } \\
\text { resultan determinantes, como } \\
\text { la intencionalidad humana. }\end{array}$ \\
\hline $\begin{array}{l}\text { Problemas para utilizar las } \\
\text { conclusiones sobre el presente } \\
\text { en un análisis del pasado. }\end{array}$ & $\begin{array}{l}\text { Proyectar una representación } \\
\text { gráfica de las conclusiones del } \\
\text { trabajo previo, con el objetivo } \\
\text { de observar de forma más clara } \\
\text { los cambios que se producen al } \\
\text { introducir nuevos conceptos en } \\
\text { el análisis. }\end{array}$ & $\begin{array}{l}\text { Al trabajar sobre una base } \\
\text { construida por los propios } \\
\text { estudiantes, se observa un } \\
\text { claro progreso al elaborar una } \\
\text { nueva explicación, obteniendo } \\
\text { un mayor grado de compleji- } \\
\text { dad y coherencia al analizar los } \\
\text { hechos. }\end{array}$ \\
\hline
\end{tabular}

Fuente: Elaboración propia 
que existen ciertas dificultades a la hora de interpretar factores imprescindibles como las motivaciones humanas, y ello a pesar de que el trabajo se basaba en reconstrucciones hipotéticas donde cada alumno podía aportar todo aquello que considerara importante. Indudablemente, el hecho de pasar por alto esta cuestión es fruto, ante todo, de una formación disciplinar donde aptitudes como la interpretación y la empatía no han recibido demasiada atención, por lo que su tratamiento les resulta, por desconocido, difícilmente aplicable. En este sentido, el recurso de la comparación con el presente resultó útil para sacar a la superficie esos contenidos implícitos; empero, un porcentaje importante de los estudiantes (42\%) siguió manifestando problemas para integrar en la misma explicación causas e intenciones; situación que muestra la conveniencia de seguir trabajando en este asunto.

En cualquier caso, lo más importante es que se aprecia una mejora notable fruto de la incorporación sucesiva de nuevos elementos al análisis que, siguiendo una complejidad progresiva mediada por el profesor, otorga al estudiante un papel activo como constructor de conocimiento. En el gráfico (Fig. 4) se muestra la evolución seguida por los futuros maestros, comparando los resultados iniciales con los que se desprenden de su explicación final. Puede observarse cómo al término de la intervención, la totalidad de participantes dominaban el tercer nivel de complejidad (ver cuadro 1), es decir, la formulación de hipótesis para explicar las causas que pudieron incidir en un hecho; y por otra parte, cómo un 58\% había logrado construir una explicación integrada combinando elementos causa-

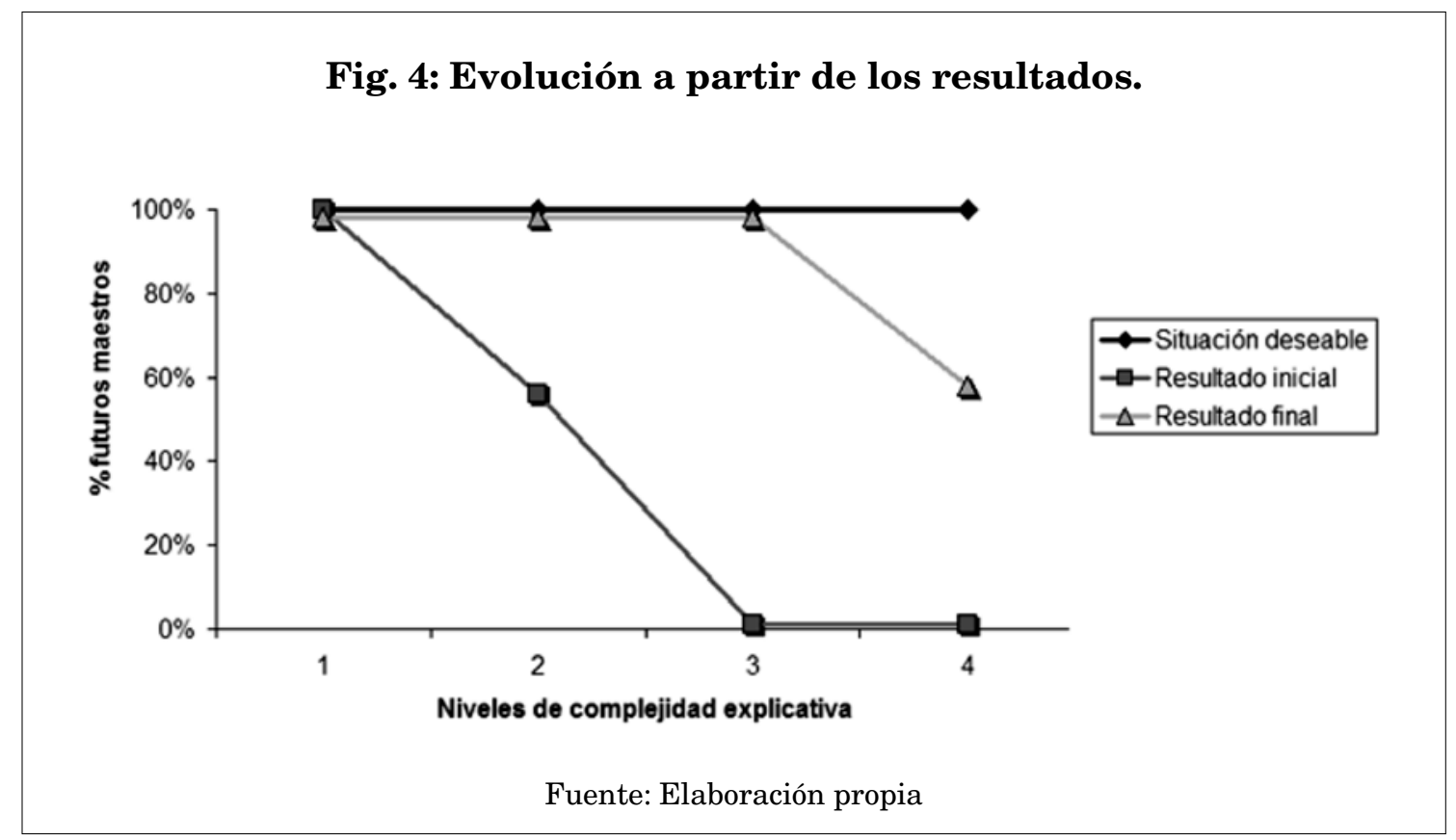


les y teleológicos, lo que se corresponde con el mayor nivel de complejidad. De forma que se consiguió un tránsito desde la simple descripción (enumeración de características) a una explicación derivada de diversas hipótesis, argumentada y que comprende la complejidad de relaciones causales e intencionales que dan coherencia a los hechos.

\section{Resultados de la intervención a partir de las reflexiones de los futuros maestros}

Aunque nosotros percibimos una evolución satisfactoria, era necesario conocer las opiniones de los futuros maestros, ya que en definitiva, serán ellos quienes decidan incorporar o no esta experiencia a su práctica docente.

Entre los aspectos positivos que señalaron los participantes se encuentra el hecho de que este tipo de ejercicios permiten entender que, realmente, «la historia puede ayudarnos a conocer algunos problemas que todavía hoy nos afectan», porque si bien la disciplina «se ocupa del pasado, algunas cosas no han cambiado en el presente y analizarlas facilita su comprensión e incluso, por qué no, concienciarse para intentar solucionarlos». Ello confirma que esta experiencia, a modo de introducción a la didáctica de la Historia, resulta útil para aproximar a los futuros maestros a uno de los pilares básicos de la disciplina. Asimismo, se encuentran referencias al cambio de perspectiva entre memorizar informaciones históricas e indagar en cómo se construyen, resaltando la importancia del trabajo colaborativo y de conceder al estudiante un papel más activo: «las relaciones entre los hechos son complicadas y de distinto tipo. Por eso conviene que el alumno haga un esfuerzo por desvelarlas y luego, con nuestra ayuda y las ideas de sus compañeros, llegar a conclusiones válidas». También se considera útil «ir proyectando los resultados para ver claramente el progreso que se va haciendo", al tiempo que "podrían utilizarse los hechos destacados [en referencia a los ítems incluidos en los esquemas causales] para extraer más hipótesis y relaciones entre ellos y hacer más completa la explicación».

Por otro lado, es destacable cómo los aspectos que se consideran negativos se orientan hacia las dificultades para aplicar este modelo en la enseñanza de la historia en Primaria. Fundamentalmente, los estudiantes manifestaron que «habría que hacer adaptaciones para poder utilizarlo con niños teniendo en cuenta también los contenidos del libro» $\mathrm{y}$, en cualquier caso, «no habría suficiente tiempo para tratar todos los temas con este sistema, porque además de formular las hipótesis habría que confirmar que son ciertas, lo que llevaría bastante tiempo».

Sin duda, se produce una discordancia entre los propósitos de la actividad y la percepción que de ella tienen los futuros maestros. En efecto, nuestra intención no era trabajar estrategias para la enseñanza de la historia en Primaria, sino justificar, mediante un ejemplo concreto, la base epistemológica de lo que aprenderían posteriormente sobre la didáctica de la disciplina. En cambio, aunque la experiencia sirvió para comprender el verdadero objetivo de la Historia, no parece que esto se valorara 
como imprescindible para la docencia, ya que no encontramos referencia alguna a la necesidad o beneficios de conocer los fundamentos de lo que se enseña. Lo cual, reafirma nuestra convicción sobre la conveniencia de incorporar la aproximación a la epistemología disciplinar como un asunto básico e ineludible en la formación inicial de maestros.

No obstante, cabe señalar el hecho de que las preocupaciones se dirijan hacia la falta de tiempo y cómo adecuar el modelo para los niveles básicos, pues indica que, pese a todo, el problema no es endógeno (del propio modelo en sí), sino que deriva de factores exógenos (condicionantes para su adaptación y aplicación). Se abre así la puerta para nuevos trabajos que profundicen no sólo en la posibilidad de adaptar este modelo causal a la enseñanza Primaria (perfectamente factible mediante una estructura progresiva como la que se propone en Prats, 2001: 31-33 o en Pozo, Asensio y Carretero, 1989: 238), sino también en la relación contenidos/temporalización que, finalmente, den lugar a propuestas para una organización curricular más acorde con los tiempos y necesidades actuales.

\section{Conclusiones}

Partíamos de que en los niveles preuniversitarios, el potencial educativo de la historia sólo adquiere plena significatividad si se hace explícito; para lo cual, es imprescindible aprehender el verdadero significado de la utilidad que se atribuye a la disciplina.

A este respecto, los futuros docentes deben conocer cómo se construye el conocimiento histórico, ya que la epistemo- logía es la que confiere sentido a todos los aprendizajes que de ella se deriven y que serán transmitidos a los estudiantes más jóvenes. Es decir, se trata de los cimientos que darán estabilidad y coherencia al proceso de enseñanzaaprendizaje. En este caso, la intervención que desarrollamos ha de entenderse como una primera aproximación al trabajo del historiador, con el objetivo de profundizar en algunos métodos básicos, conocer las dificultades que entraña su aplicación y comprobar hasta qué punto puede contribuir a mejorar la práctica docente. Por supuesto, una vez hecho este ejercicio, el siguiente paso debería dirigirse a contrastar, con fuentes de información fidedignas (el libro de texto, recursos de Internet, fragmentos de otros textos, etc.), los resultados iniciales a los que llegan los participantes; algo que los propios estudiantes de Magisterio demandaban, confirmando lo que apuntábamos anteriormente: la formulación de hipótesis sobre hechos que se desconocen o sobre los que se tiene un vago recuerdo, favorece una transición más natural hacia uno de los aspectos clave de la disciplina como es la crítica y selección de fuentes.

Por otra parte, los resultados revelan cómo a partir de un hecho histórico concreto pueden articularse acciones fundamentales como la formulación de hipótesis, el análisis de las relaciones causa-efecto que permiten explicar los hechos y, en definitiva, la construcción de discursos históricos coherentes, todo ello otorgando a los estudiantes un papel protagonista. Asimismo, las referencias al presente han demostrado ser útiles para desvelar nuevos elementos 
que requieren la implementación de procesos interpretativos y empáticos, como las motivaciones humanas, que pueden influir o desencadenar distintos hechos; pero también para hacer explícito parte del potencial educativo de la historia en su vertiente más crítica, al identificar, mediante relaciones de continuidad entre el pasado y el presente, ciertos problemas actuales sobre los que sería posible actuar.

Sin embargo, el trabajo ha puesto de manifiesto que la epistemología disciplinar, como objeto de estudio en sí mismo, no ha sido valorada por los futuros maestros como un aspecto clave. Esto se aprecia claramente en el hecho de que sus comentarios finales giran en torno a la aplicación del método expuesto, pero no encontramos referencias acerca de su relevancia o no para ejercer la docencia. En efecto, aunque se ha logrado que conozcan el verdadero potencial educativo de la historia, su aprovechamiento queda supeditado a unas condiciones que les vendrán dadas (falta de tiempo, contenidos del libro de texto, etc.) sobre las cuales, asumen que no tendrán ninguna capacidad de decisión. De esta forma, se muestra un mayor interés por el qué y cómo enseñar, asuntos de innegable importancia, pero que acaban eclipsando al por qué y para qué enseñar, que son las preguntas que realmente pueden conducir a una reflexión y transformación efectiva de la propia práctica docente (Schön, 1992 y 1996). Por tanto, parece claro que, ante la dificultad que plantea, debemos promover explícitamente esa reflexión sobre todo en la formación inicial de los docentes, incidiendo en la necesidad de no supedi- tar la enseñanza a un contexto determinado, sino de adaptarla a él para transformarlo a mejor.

Evidentemente, en un sistema como el actual, donde prima el memorismo sobre todo lo demás, esta última cuestión acaba diluyéndose en la inutilidad al no considerarse como imprescindible (porque de hecho, no lo es). Por eso, no podemos finalizar este escrito con una conclusión cerrada, sino con el propósito de seguir trabajando en esta cuestión. Así, terminamos formulando unas preguntas que, precisamente, pretenden invitar a esa necesaria reflexión. La primera hace referencia a una idea que ha sido mencionada anteriormente: ¿Puede enseñarse una disciplina cuyos fundamentos más básicos son considerados como secundarios para la docencia? En este caso, habida cuenta del modelo que predomina en las aulas, podría responderse afirmativamente, pero entonces deberemos enfrentarnos a un dilema: ¿Es lícito exigir a los alumnos que adquieran unos conocimientos sin haber reflexionado sobre por qué se les exige o para qué necesitan aprenderlos? De la respuesta, sin duda, dependerá la pervivencia de ese modelo anacrónico e ineficaz o el comienzo de una transformación que hoy es más necesaria que nunca.

\section{Referencias bibliográficas}

ASHBY, R.; LEE, P. J. y SHEMILT, D. (2005): "Putting Principles into practice: Teaching and planning”, en Donovan, S. y Bransford, J. (eds.): How students learn: History in the classroom, Washington: National Research Council, pp. 79-178. 
CARRETERO, M. (2002): Construir y enseñar. Las Ciencias Sociales y la Historia, Buenos Aires: Aique.

CARRETERO, M. y VOSS, J. (coords.) (2004): Aprender y pensar la historia, Madrid: Amorrortu.

FELIU, M. y SALLÉS, N. (2011): “El método científico para enseñar Historia: una experiencia en la formación de maestros", en Clío, n. 37 (http://clio.rediris.es).

FONTANA, J. (1973): La Historia, Barcelona: Salvat Editores.

GONZÁLEZ MANGRANÉ, M. I. (1993):

La enseñanza de la Historia en el Bachillerato: la visión de los alumnos, Tesis doctoral inédita, dirigida por Mario Carretero, Facultad de Geografía e Historia, Universidad de Barcelona (Lleida).

GUIMERÀ, C. (1991): Práctica docente $y$ pensamiento del profesor de Historia de Secundaria, Tesis doctoral inédita, dirigida por Mario Carretero, Facultad de Geografía e Historia, Universidad de Barcelona (Lleida).

HABERMAS, J. (1987): Teoría de la acción comunicativa, Madrid: Taurus.

LEE,P.J.(2005): "Putting Principles into practice: Understanding History", en Donovan, S. y Bransford, J. (eds.): How students learn: History in the classroom, Washington: National Research Council, pp. 31-78.

LEVSTIK, L. y BARTON, K. (2005): Doing History: Investigating with children in Elementary and Middle Schools, Nueva Jersey: Lawrence Erlbaum Associates.
MERCHÁN, F. J. (2002): "El estudio de la clase de Historia como campo de producción del currículo", en Enseñanza de las Ciencias Sociales. Revista de investigación, n. 1, Barcelona: ICE Universidad Autónoma de Barcelona/ICE Universidad de Barcelona, pp. 41-54.

MERCHÁN, F. J. (2007): "El papel de los alumnos en la clase de historia como agentes de la práctica de la enseñanza", en Didáctica de las Ciencias Experimentales y Sociales, n. 21, Valencia: Servicio de Publicaciones de la Universidad de Valencia, pp. 33-51.

MONTANERO, M. y LEÓN, J. A. (2004): "La comprensión de textos multicausales en el área de ciencias sociales", en Revista de Educación, n. 333, Madrid: Ministerio de Educación, pp. 409-424.

MONTANERO, M; LUCERO, M. y MÉNDEZ, J. M. (2008): "La causalidad histórica en las explicaciones de los profesores de Secundaria", en Cultura y Educación, vol. 20, n. 2, Fundación Infancia y Aprendizaje, pp. 161-179. http://dx.doi. org/10.1174/113564008784490398

MORADIELLOS, E. (2011): "La historia: una ciencia humana y social de naturaleza racional constructivista", en Prats, J. (coord.): Geografía e Historia. Complementos de formación disciplinar, Barcelona: Graó, pp. 33-45.

PAGÉS, J. (2004): “Enseñar a enseñar Historia: la formación didáctica de los futuros profesores", en Gómez 
Hernández, J. A. y Nicolás Marín, M. E. (coords.): Miradas a la Historia. Reflexiones historiográficas en recuerdo de Miguel Rodríguez Llopis, Murcia: Servicio de Publicaciones de la Universidad de Murcia, pp. 155-178.

PAGÈS, J. (2006): "La comparación en la enseñanza de la Historia", Clío y Asociados. La Historia enseñada, n. 9-10, Santa Fe (Argentina): Servicio de Publicaciones de la Universidad Nacional del Litoral, http://www. didacticahistoria.org/EVEH/index. htm.

POZO, J. I.; ASENSIO, M. y CARRETERO, M. (1986): “¿Por qué prospera un país? Un análisis cognitivo de las explicaciones en Historia", en Infancia y Aprendizaje, n 34, pp. 23-41.

POZO, J. I; ASENSIO, M. y CARRETERO, M. (1989): "Modelos de aprendizaje-enseñanza de la Historia", en Carretero, M.; Pozo, J. I. y Asensio, M. (comp.): La enseñanza de las Ciencias Sociales, Madrid: Visor, pp. 211-239.

PRATS, J. (1997): "La selección de contenidos históricos para la educación secundaria", en Íber: Didáctica de las Ciencias Sociales, geografía e historia, n. 12, Barcelona: Graó, pp. 7-18. PRATS, J. (2001): Enseñar historia. Notas para una didáctica renovadora, Mérida: Junta de Extremadura.

PRATS, J. y SANTACANA, J. (2011): "Por qué y para qué enseñar Histo- ria”, en Prats, J. (coord.): Didáctica de la Geografía y la Historia, Barcelona: Graó, pp. 13-29.

SANTACANA, J. (2005): "Reflexiones en torno al laboratorio escolar de ciencias sociales", en Íber: Didáctica de las Ciencias Sociales, geografía e historia, n. 43, pp. 7-16.

SCHÖN, D. (1992): La formación de profesionales reflexivos. Hacia un nuevo diseño de la enseñanza y el aprendizaje de las profesiones, Barcelona: Paidós.

SCHÖN, D. (1996): "La crisis del conocimiento profesional y la búsqueda de una epistemología de la práctica”, en Pakman, M. (comp.): Construcciones de la experiencia humana. Volumen I, Barcelona: Gedisa, pp. 183-197.

VALLS, R. (2004): "La enseñanza de la Historia: Entre polémicas interesadas y problemas reales", en Gómez Hernández, J. A. y Nicolás Marín, M. E. (coords.): Miradas a la Historia. Reflexiones historiográficas en recuerdo de Miguel Rodríguez Llopis, Murcia: Servicio de Publicaciones de la Universidad de Murcia, pp. 141-154.

VALLS, R. y LÓPEZ FACAL, R. (2011): "La didáctica de la Historia y la Geografía como reflexión para la educación actual. Perspectiva histórica", en Prats, J. (coord.): Geografía e Historia. Complementos de formación disciplinar, Barcelona: Graó, pp. 189-199. 
